\title{
Editorial
}

\section{Relevância da Bioética para a Cooperação Internacional em Saúde}

A reconfiguração das relações internacionais na transição para o século 21, embora apresente marcante transformação do quadro geopolítico da bipolaridade leste-oeste e norte-sul que se instalou no pós II Guerra Mundial, mantém como traço predominante as condições de desigualdade e dependência nas relações políticas, econômicas e militares que separam um pequeno grupo de nações dentre as duas centenas de integrantes do sistema das Nações Unidas. Tal característica modula os processos de cooperação, assistência ou ajuda externa praticados no seio dessa comunidade de países, cuja diversidade semântica é reveladora dos padrões de dependência e heteronomia, em contraposição aos ideais de equidade e autonomia que poderiam orientar as relações entre os países envolvidos nesses processos.

O fortalecimento dos interesses entre países em desenvolvimento constitui um elemento cada vez mais importante no novo cenário das relações internacionais, num processo histórico que há várias décadas congrega as nações majoritariamente situadas no hemisfério sul, razão pela qual esse processo vem sendo reconhecido como instituinte do Sul Global ${ }^{1}$. Cenário no qual os países pretendem construir projetos de cooperação, agora designados pelo sufixo sul-sul, que correspondam a seus próprios desígnios de desenvolvimento.

O novo enfoque da cooperação sul-sul na área da saúde germinou no bojo desse processo, contaminado virtuosamente pelo princípio da solidariedade voltado para a redução das desigualdades entre os países, de forma associada ao postulado da saúde como direito humano e não apenas como resultante do processo de desenvolvimento a ser estimulado via cooperação externa. Nesse sentido, as experiências reais desse novo paradigma de cooperação devem enfrentar os dilemas bioéticos aí presentes, gerados na intersecção entre os interesses diplomáticos dos Estados e os princípios de equidade, justiça e solidariedade em torno da saúde como direito humano.

As avaliações sobre as condições de vida e saúde nas diferentes partes do mundo revelam discrepâncias entre os padrões de bem estar e riqueza e as condições sanitárias da maioria das populações, suscitando considerações éticas tanto na explicação desses problemas como na escolha de alternativas para equacionamento dos mesmos. As tensões no campo das relações internacionais circunscrevem de forma cada dia mais preocupante questões relacionadas à saúde vis-à-vis o desenvolvimento científico e tecnológico,

UNITED NATIONS DEVELOPMENT PROGRAMME. Forging a global south. United Nations Day for south-south cooperation. 19 december 2004. Disponível em: www. undp.org.cn/downloads/ssc/forgingaglobalsouth.pdf. Acesso em: 07 jul. 2011 
com graves implicações bioéticas a exemplo da regulação de pesquisas envolvendo seres humanos, o controle de armas biológicas, o reconhecimento de patentes de produtos de consumo humano e tantos outros.

Vários documentos internacionais pautam a relevância da bioética no contexto das relações entre os países. A Declaração Universal sobre Bioética e Direitos Humanos aborda especificamente o tema da responsabilidade dos Estados na cooperação internacional voltada para o compartilhamento solidário dos benefícios do desenvolvimento técnico e científico. A Declaração de Alma-Ata propugnou a "redução da lacuna existente entre o estado de saúde dos países em desenvolvimento e o dos desenvolvidos" e "que os cuidados primários de saúde sejam desenvolvidos e aplicados em todo o mundo e, particularmente, nos países em desenvolvimento, num espírito de cooperação técnica e em consonância com a nova ordem econômica internacional". Esse elenco de convenções culmina com a Declaração da ONU sobre os oito Objetivos de Desenvolvimento do Milênio, ao incluir quatro compromissos diretamente relacionados à saúde (erradicar a extrema pobreza e a fome; reduzir a mortalidade na infância; melhorar a saúde materna; combater o HIV/ Aids, a malária e outras doenças), e três outros que constituem fatores associados (atingir o ensino básico universal; promover a igualdade entre os sexos e a autonomia das mulheres; garantir a sustentabilidade ambiental), além do último (estabelecer uma parceria mundial para o desenvolvimento) que diz respeito à solidariedade e, portanto, à cooperação internacional.

A contribuição da bioética para a formulação, execução e avaliação da cooperação sul-sul como concretização do ideário das relações internacionais balizadas pela solidariedade, consenso e equidade representa um desafio ante a situação e tendências da saúde na Terra. Desafio convertido em convite para a reflexão e para a ação que se apresenta neste editorial aos leitores da Revista Brasileira de Bioética, pesquisadores e estudiosos da Bioética e aos congressistas do IX Congresso Brasileiro de Bioética e I Congresso Brasileiro de Bioética Clínica.

\title{
José Paranaguá de Santana \\ Oficial nacional da OPAS/OMS, Representação do Brasil. Assessor técnico principal do projeto NETHIS (Núcleo de Estudos sobre Bioética e Diplomacia em Saúde). Doutorando em Bioética no PPG/FS/UnB.
}

\author{
José Roberto Ferreira \\ Coordenador da Assessoria de Cooperação Internacional, Centro de Rela- \\ ções Internacionais em Saúde da Fiocruz.
}

